\title{
Unified ZnO Q-dot growth mechanism from simultaneous UV-Vis and EXAFS monitoring of sol-gel reactions induced by different alkali base
}

\author{
Bruno L. Caetano ${ }^{\text {a, b, **, }}$, Marlon N. Silva a , Celso V. Santilli a, Valérie Briois ${ }^{b}$, \\ Sandra H. Pulcinelli ${ }^{\text {a }}$ * \\ a Instituto de Química, UNESP, Rua Professor Francisco Degni, 55, 14800-900, Araraquara, SP, Brazil \\ b Synchrotron SOLEIL, L'Orme des Merisiers, BP48, Saint Aubin, 91192, Gif-sur Yvette, France
}

\section{A R T I C L E I N F O}

\section{Article history:}

Received 18 January 2016

Received in revised form

20 June 2016

Accepted 21 June 2016

Available online 4 July 2016

\section{Keywords}

$\mathrm{ZnO}$

Q-dot

Photoluminescence

Ostwald ripening

Oriented attachment

UV-Vis

EXAFS

\begin{abstract}
A B S T R A C T
This article aims to give experimental evidences of the universality of main steps involved in $\mathrm{ZnO}$ nanoparticles formation and growth from sol-gel process. In this way, we revisit the effect of the alkali base ( $\mathrm{LiOH}, \mathrm{NaOH}, \mathrm{KOH}$ ) used to induce the hydrolysis-condensation reaction in order to unfold the $\mathrm{ZnO}$ Q-dot formation mechanisms by using simultaneous time resolved monitoring of zinc species and Q-dot size by combining EXAFS and UV-Vis spectroscopy. Irrespective of the alkali base used, nucleation and growth of $\mathrm{ZnO}$ Q-dots occur by consumption of zinc oxy-acetate precursor. Higher amounts of $\mathrm{ZnO}$ nanocrystal are produced as the strength of the base increases. After achieving the steady state equilibrium regime the Q-dot growth occurs initially by oriented attachment coalescence mechanism followed by the Ostwald ripening coarsening. The dependence of the formation and growth mechanisms on the base strength allows the fine tuning of the Q-dot size and photoluminescence properties.
\end{abstract}

(c) 2016 Elsevier B.V. All rights reserved.

\section{Introduction}

Quantum dots (Q-dot) are semiconductor nanocrystals, which radius is of the same order of the exciton Bohr radius, so they are so small they are considered dimensionless. It is a very beautiful material because the wavelength of the emitted light can be tuned by changing the nanocrystal size. The smaller the Q-dot size, the bigger the semi-conductor band gap, and consequently, the energy of the emitted light. The technology concerning nanocrystal semiconductor emerged in the early 1980s from the contribution of Brus [1] and Efros [2] to the understanding of the quantum confinement effect that explains the correlation between size and the color of light emitted by these nanocrystals. The origin of the fluorescence of Q-dot is the formation of excitons, or Coulomb correlated electron-hole pairs with Bohr radius bigger than the radius of

\footnotetext{
* Corresponding author.

** Corresponding author. Instituto de Química, UNESP, Rua Professor Francisco Degni, 55, 14800-900, Araraquara, SP, Brazil.

E-mail addresses: caetanobruno@yahoo.com.br (B.L. Caetano), sandrap@iq. unesp.br (S.H. Pulcinelli).
}

nanocrystal. Typical semi-conductors presenting this striking property are cadmium selenium and cadmium tellurium alloys, zinc sulfide and zinc oxide [1-4].

The predicted exciton size of $\mathrm{ZnO}$ is about $6 \mathrm{~nm}$, its bulk band gap energy is $\approx 3.37 \mathrm{eV}$ corresponding to an absorption threshold at $\approx 370 \mathrm{~nm}$ [1]. So, as particles grow up to sizes of about $6 \mathrm{~nm}$, the wavelength of the absorption edge will be red-shifted to the bulk value. However, the mechanisms controlling the $\mathrm{ZnO}$ nanocrystal growth in the colloidal systems are not yet clearly understood.

During the last decades, a renewed interest in the synthesis of $\mathrm{ZnO}$ Q-dot with tunable size by using an easy and inexpensive solgel route has emerged [5-10]. A very easy sol-gel route to synthesize zinc oxide nanocrystals was proposed by Spanhel and Anderson in the 1990s [11]. This is a two-step route: the first one consisting of thermal dehydration of zinc acetate in ethanol and the formation of a cyclic tetramer of zinc oxy-acetate [12], the second step consists of inducing the polycondensation of this precursor, giving rise to zinc oxide nanoparticles $[13,14]$. The particle size of the initial sol can be tuned from 3.5 to $5.5 \mathrm{~nm}$ by aging of the colloids [9,14-16].

Some time ago, we reported the first UV-Vis and EXAFS coupled 
monitoring of the time evolution of $\mathrm{Zn}$-based species formed during aging of ethanolic zinc oxy-acetate precursor in the presence of $\mathrm{LiOH}[7,10]$. The increasing amount of $\mathrm{ZnO}$ Q-dot is evidenced by the increase in the excitonic peak intensity and also by the EXAFS oscillation structuration. Moreover, the formation of large particles was evidenced by the increase in light scattering, while the EXAFS spectra revealed the formation of zinc hydroxide double salt (ZnHDS) [7]. The time evolution of EXAFS spectra allowed us to show that the amounts of $\mathrm{ZnO}$ Q-dot and of precursor decrease while the amount of the $\mathrm{Zn}$-HDS increases as a result of the reaction between $\mathrm{ZnO}$ nanoparticles and unreacted zinc oxy-acetate [10]. As the dissolution of $\mathrm{ZnO}$ and the reprecipitation of $\mathrm{Zn}$-HDS are induced by the gradual release of water mainly produced by ethanol esterification, to maximize the reaction yield for the formation of $\mathrm{ZnO} \mathrm{Q}$-dot the amount of water has to be very well controlled to hinder the formation of the Zn-HDS phase [17,18].

The Ostwald ripening is the most frequent mechanism used to describe $\mathrm{ZnO}$ particle growth $[14,19]$ which is based on the larger solubility of the smaller particles as predicted by the OstwaldFreundlich equation used in the coarsening theory (LSW) developed by Lifshitz [20], Slyozov and Wagner [21]. Accordingly, the small particles undergo dissolution and the dissolved atoms reprecipitate at the surface of larger particles. Then, particles smaller than the average size will disappear, while the larger ones will become bigger and bigger, following a cubic power law dependency of particle radius $(R)$ with time $(t): R^{3} \propto t$. Other mechanism is the grain coalescence induced by grain re-orientation proposed from transmission electron microscopy observation of colloids nanocrystals [22]. According to this model the rotation of grains among neighbouring grains results in a coherent grain-grain interface (the grains assume the same crystallographic orientation), which leads to the coalescence of neighbouring grains forming a single larger grain.

Taking into account for the relevant features just reviewed, this article proposes to give experimental evidence of the universality of main steps involved in the process of $\mathrm{ZnO}$ nanoparticles formation and growth. In this way we revisit the effect of the alkali base $(\mathrm{LiOH}$, $\mathrm{NaOH}, \mathrm{KOH}$ ) used to induce the sol-gel reaction in order to unfold the $\mathrm{ZnO}$ Q-dot formation mechanisms by using simultaneous time resolved monitoring of zinc species and Q-dot size by combining EXAFS and UV-Vis spectroscopy.

\section{Experimental}

The $\mathrm{Zn}_{4} \mathrm{O}\left(\mathrm{CH}_{3} \mathrm{COO}\right)_{6}$ precursor was prepared by refluxing an absolute ethanolic solution containing $0.05 \mathrm{~mol} \mathrm{~L}^{-1}$ zinc acetate dihydrate $\mathrm{Zn}\left(\mathrm{CH}_{3} \mathrm{COO}\right)_{2} \cdot 2 \mathrm{H}_{2} \mathrm{O}$ for $3 \mathrm{~h}$ at $80{ }^{\circ} \mathrm{C}$ as described previously [12]. $\mathrm{LiOH}, \mathrm{NaOH}$ and $\mathrm{KOH}$ ethanolic solutions were used to induce hydrolysis and condensation reactions at $\mathrm{T}=40{ }^{\circ} \mathrm{C}$ with a constant nominal hydrolysis ratio $[\mathrm{MOH}] /[\mathrm{Zn}]=0.5(\mathrm{M}=\mathrm{Li}$, Na and $\mathrm{K})$. The quantity of water was controlled $\left(\left[\mathrm{H}_{2} \mathrm{O}\right] /[\mathrm{Zn}]=2\right)$ to ensure that the only phase formed was the zinc oxide. Under this synthesis conditions we avoid the aggregation and subsequent settling of $\mathrm{ZnO}$ Q-dot as well as the formation of zinc hydroxide double salt observed at high water quantity $\left(\left[\mathrm{H}_{2} \mathrm{O}\right] /[\mathrm{Zn}]=20\right)$, as verified in an early study [7].

The photoluminescence (PL) and excitation (PE) spectra of suspensions collected at selected reaction times were recorded at $25{ }^{\circ} \mathrm{C}$ with a spectrofluorimeter SPEX (Fluorolog F2121) using a continuum xenon lamp (450 W), a double monochromator SPEX (model1680) and a photomultiplicator R928 Hamamatsu. The emitted light was detected in front face mode and appropriated filters were installed in both the excitation and emission light paths. For PL measurements, each sample was excited at the wavelength corresponding to the maximum of the PE spectrum.
For the simultaneous monitoring by UV-Vis and EXAFS, hydrolysis and condensation reactions were carried out in a specially designed liquid cell [23]. UV-Vis data were recorded in the 240-540 nm wavelength range using the Varian Cary 50 dualbeam spectrometer fitted with an optic fiber coupler connected to an immersion probe during the first hours of reaction. The data collection was carried out in a step scanning continuous way with a step interval of $1 \mathrm{~nm}$, an average time of $0.1 \mathrm{~s}$ per point and a time framing of $1 \mathrm{~min}$. UV-Vis data were used to calculate the radius of $\mathrm{ZnO}$ Q-dot from the effective mass model [1]. As fully explained in Ref. [8] the average Q-dot radius can be obtained from the cutoff wavelength determined by the intersection of the tangent of the excitonic peak threshold with the wavelength axis after the removal of the absorbance tail associated to the scattering effect.

Simultaneously, EXAFS measurements at the $\mathrm{Zn} \mathrm{K}$ edge were recorded at the SAMBA beamline at the Soleil synchrotron (SaintAubin, France) in transmission mode using a Si(111) double crystal monochromator with a collection time to about $210 \mathrm{~s}$ for a whole XAFS spectra. Linear Combinations (LC) of normalized EXAFS spectrum including the edge were carried out in order to determine the composition of the colloidal suspensions at any stage of the reaction. Size-calibrated $\mathrm{ZnO} \mathrm{Q}$-dot and the initial zinc oxy-acetate precursor solution before the addition of the base were used as main components for simulating, by LC, the normalized EXAFS spectra of colloidal suspensions during the $\mathrm{ZnO}$ formation and growth. The software package Athena [24] was used to proceed the analysis of the EXAFS data following the method fully explained in Ref. [9].

\section{Results and discussion}

Fig. 1 shows the time evolution of the photoexcitation (PE) and photoluminescence (PL) spectra measured at different time periods of $\mathrm{ZnO}$ colloids synthesis from the sol-gel route. As the sample is converted from the precursor solution to the colloids the PE peak becomes thinner and is red-shifted. This behavior is characteristic of electron-hole excitons by the Q-dot of growing sizes. It is noteworthy that the maximum observed for the PE peak after 5 min of reaction for samples prepared with $\mathrm{LiOH}$ and $\mathrm{NaOH}$ occurs at a wavelength lower $(285-288 \mathrm{~nm}$, Q-dot radii $=1.25-1.27 \mathrm{~nm})$ than that observed for the sample hydrolyzed with $\mathrm{KOH}(300 \mathrm{~nm}$, Q-dot radii $=1.37 \mathrm{~nm}$ ). This is an evidence that the addition of $\mathrm{KOH}$ favors the fast growth of Q-dot. Note that after $2 \mathrm{~h}$ of reaction the PE spectrum of the sample prepared with $\mathrm{KOH}$ is characterized by two peaks; the most intense occurs at $333 \mathrm{~nm}$ and the less intense at the same position of the peak observed after $5 \mathrm{~min}$. This behavior indicates the presence of two families of particles, with average Q-dot sizes of 1.37 and $1.79 \mathrm{~nm}$. The peak observed at lower wavelength appears as a shoulder both for reactions hydrolyzed with $\mathrm{LiOH}$ and $\mathrm{NaOH}$. Even after $18 \mathrm{~h}$ of reaction this shoulder is observed as a broad tail at the left side of the main peak, irrespective of the base, indicating the persistence of a broad size distribution of small Qdot. As it will be discussed in the following, the formation of a double family of Q-dot is the manifestation of the Q-dot coalescence, while the broad size distribution is an essential condition for the coarsening by the Ostwald-ripening mechanism.

The PL spectra is red shifted as the reaction time increases, i.e., the PL band maximum shifts from $\approx 499$ to $\approx 560 \mathrm{~nm}$ as the reaction time increases from 5 to $1080 \mathrm{~min}(18 \mathrm{~h})$, for the samples hydrolyzed with $\mathrm{LiOH}$ and $\mathrm{NaOH}$. A faster growth of Q-dot for the sample hydrolyzed with $\mathrm{KOH}$, is confirmed by the PL band maximum red-shifting from $\approx 503$ to $\approx 565 \mathrm{~nm}$. Moreover, the FWHM (Full Width at Half Maximum) of the PL band is essentially time invariant for the sample hydrolyzed with $\mathrm{LiOH}(\approx 155 \mathrm{~nm})$, shows a slight increase for that hydrolyzed with $\mathrm{NaOH}$ (from 

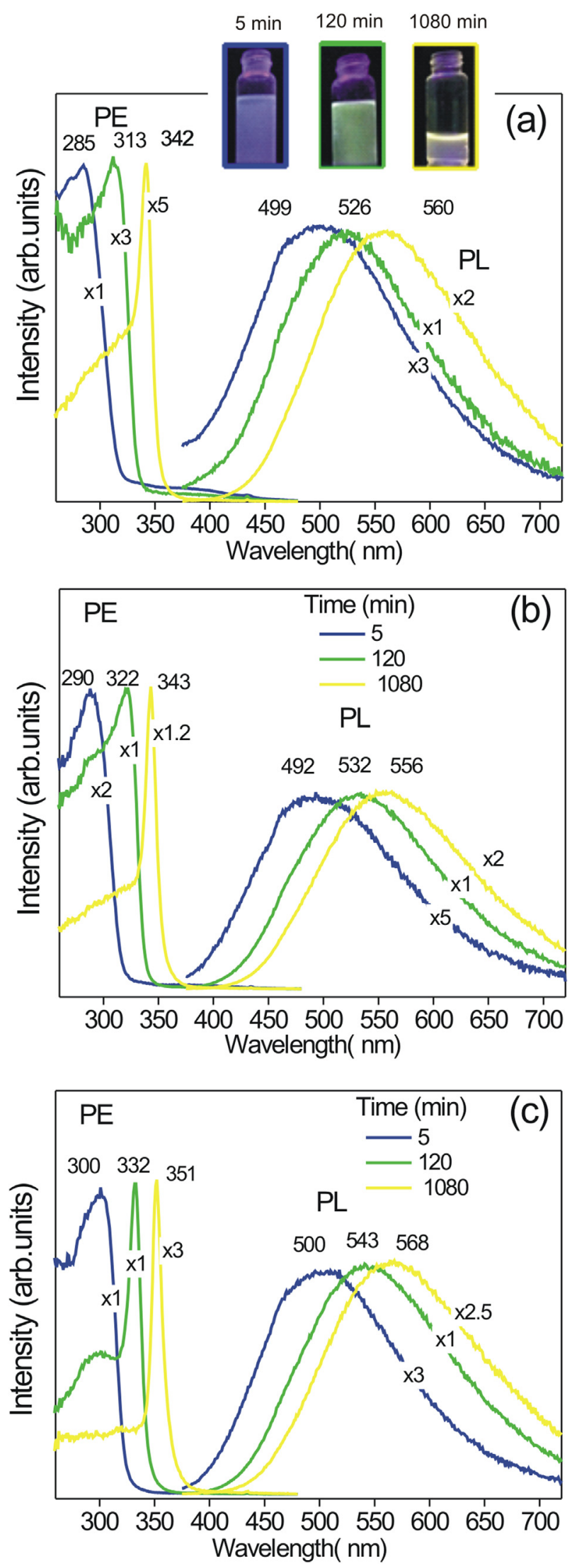

Fig. 1. Normalized PE and PL spectra of $\mathrm{ZnO}$ colloidal suspensions prepared with the addition of $\mathrm{LiOH}(\mathrm{a}), \mathrm{NaOH}$ (b) and $\mathrm{KOH}$ (c) as hydrolyzing agent measured at selected reaction times. The normalization factors are indicated near to each spectrum. Images of the samples excited at $365 \mathrm{~nm}$ are also displayed. $\approx 157 \mathrm{~nm}$ at $5 \mathrm{~min}$ to $\approx 166 \mathrm{~nm}$ after $1080 \mathrm{mim}$ ) and a pronounced increase for samples prepared with $\mathrm{KOH}$ (from $\approx 150$ at $5 \mathrm{~min}$ to $\approx 171 \mathrm{~nm}$ after $1080 \mathrm{~min}$ ). This feature indicates that the size distribution of the resulting Q-dot is nearly time invariant using $\mathrm{LiOH}$ and continually broadens in presence of $\mathrm{KOH}$. As it can be seen in the pictures of samples displayed in the top of Fig. 1, the main colours of the visible spectra (excepting for the red) can be achieved by the tuning of the $\mathrm{ZnO} \mathrm{Q}$-dot size.

The effect of the nature of alkali base in the time evolution of optical properties of the colloidal system was evaluated by UV-Vis monitoring. The absorption spectra of colloids prepared with $\mathrm{LiOH}$ and $\mathrm{NaOH}$ are displayed in Fig. 2(a) and (b), respectively. The observed time evolution of the absorption spectra is similar to that reported for ZnO colloids prepared with $\mathrm{KOH}$ [9]. Essentially, we observe a red shift of the excitonic peak evidencing a decrease in the band gap energy due to the $\mathrm{ZnO} \mathrm{Q}$-dot size growth irrespective of the base nature. However, this evolution is faster for the first four spectra measured during the first $20 \mathrm{~min}$. We note that from $5 \mathrm{~min}$ the amplitude of the excitonic maxima stays essentially invariant, indicating that the total amount of $\mathrm{ZnO}$ forming the quantum dot is kept almost constant. The first and the last recorded spectra make evident the red-shifting; from $\approx 306$ to $\approx 334 \mathrm{~nm}$ after 500 min of LiOH base addition (Fig. 2a), while for the $\mathrm{NaOH}$ (Fig. 2(b)) this shift is higher reaching $\approx 342 \mathrm{~nm}$ after $500 \mathrm{~min}$. For sample prepared with $\mathrm{KOH}$ a second regime was observed after 500 min [9], characterized by an increase in the absorption above the excitonic peak edge. This feature was attributed to the light scattering caused by the formation of large particles or aggregates, which was also evidenced by the pronounced turbidity observed with the naked eye at the end of the reaction.

Information concerning the time evolution of the zinc species was obtained from Zn K-edge EXAFS spectra whose FT for samples prepared with $\mathrm{LiOH}, \mathrm{NaOH}$ and $\mathrm{KOH}$ are presented in Fig. 3(a) and (b), and in Ref. [9], respectively. The intensity of the peak related to the oxygen first neighbour remains essentially constant in position and intensity, whereas an increasing intensity for the peak related to the $\mathrm{Zn}-\mathrm{Zn}$ contribution at $3.23 \AA$ is observed. The invariance of the first peak is consistent with the tetrahedral oxygen coordination of both the $\mathrm{Zn}_{4} \mathrm{O}\left(\mathrm{CH}_{3} \mathrm{COO}\right)_{6}$ precursor and the $\mathrm{ZnO}$ Q-dot structures. Otherwise, the increase in the intensity of the second peak observed during the reaction time must be ascribed to an increasing quantity of $\mathrm{ZnO}$ nanocrystal. However, in the case of colloids prepared with $\mathrm{KOH}$ it was previously reported [9] that the intensity of the second peak of the EXAFS spectra continues increasing after $500 \mathrm{~min}$ of reaction. As highlighted before, from 500 min the UV-Vis spectra for these colloids is characterized by strong light scattering caused by the formation of large particles or aggregates. This behavior was attributed to the existence of a second regime of formation of $\mathrm{ZnO}$ nanocrystals observed only for the sample hydrolyzed with $\mathrm{KOH}$ [9].

From the linear combination of spectra corresponding to the ethanolic solution of $\mathrm{Zn}_{4} \mathrm{O}\left(\mathrm{CH}_{3} \mathrm{COO}\right)_{6}$ precursor and of $\mathrm{ZnO}$ colloids we were able to determine the proportion of these substances as a function of time. The time evolution of the percentage of $\mathrm{ZnO}$ nanocrystals formed by the consumption of the $\mathrm{Zn}_{4} \mathrm{O}\left(\mathrm{CH}_{3} \mathrm{COO}\right)_{6}$ precursor is shown Fig. 4(a-c) for colloids prepared with $\mathrm{LiOH}$, $\mathrm{NaOH}$ and $\mathrm{KOH}$, respectively. First of all, it is important to emphasize that during the first 5 min of the reaction almost 22,33 and $46 \%$ of the precursor was transformed in $\mathrm{ZnO}$ Q-dot in the samples hydrolyzed with $\mathrm{LiOH}, \mathrm{NaOH}$ and $\mathrm{KOH}$, respectively. It is important to note that this sequence follows the same one of the base strength increase. Thus the abrupt increase in the amount of $\mathrm{ZnO}$ Q-dot observed at the beginning of the reaction can be attributed to the high amount of $\mathrm{OH}^{-}$in the reaction media due to the base addition that favors the $\mathrm{ZnO} \mathrm{Q}-\mathrm{dot}$ nucleation. After this first period, the 

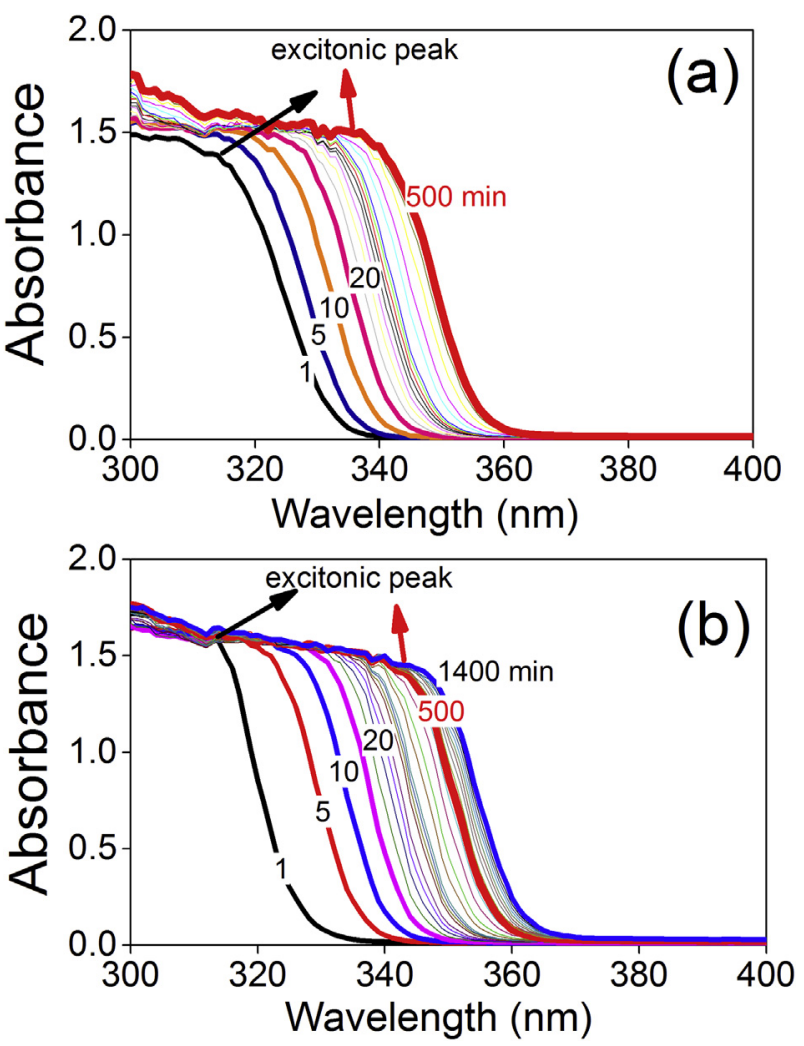

Fig. 2. Time evolution of UV-Vis absorption spectra of colloids prepared with the addition of $\mathrm{LiOH}(\mathrm{a})$ and $\mathrm{NaOH}(\mathrm{b})$ as hydrolyzing agent.
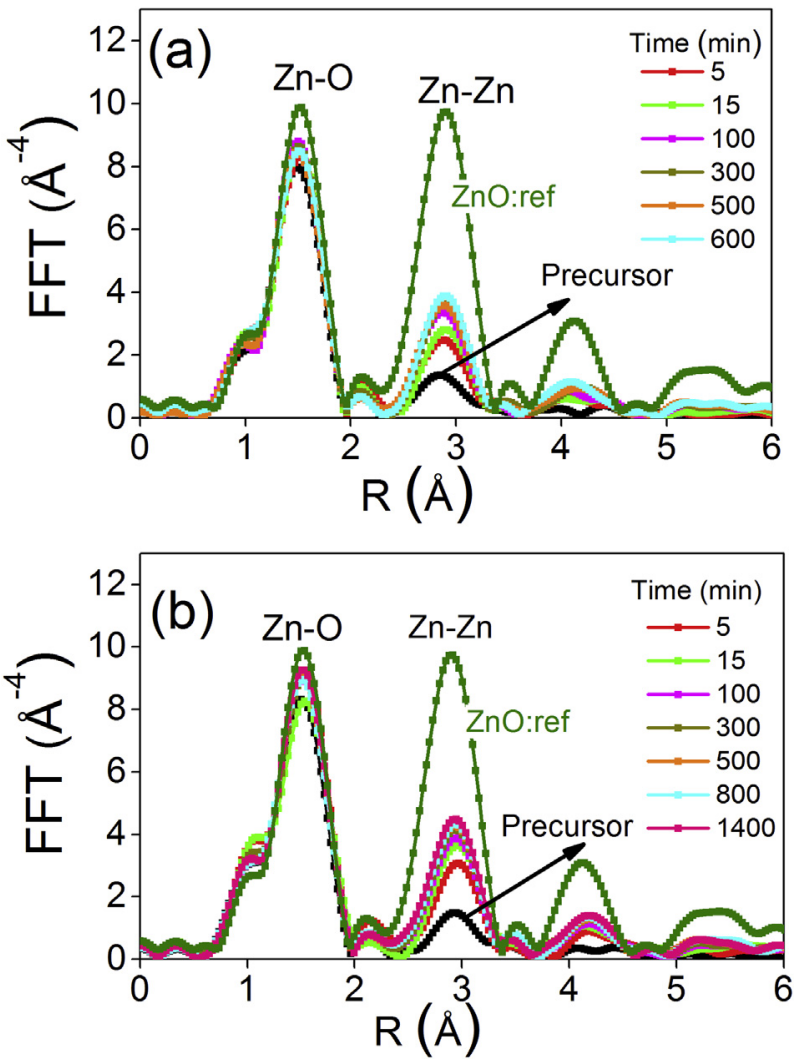

Fig. 3. Fourier transform of the EXAFS spectra of colloids prepared with $\mathrm{LiOH}$ (a) and $\mathrm{NaOH}(\mathrm{b})$ as hydrolyzing agent. time evolution of the percentage of $\mathrm{ZnO}$ nanocrystals make evident 2 different regimes for samples prepared with $\mathrm{LiOH}$ and $\mathrm{NaOH}: i$ ) From 5 to 30 min: a small increase in the fraction of $\mathrm{ZnO}$ is observed; $i$ i) from 30 min a plateau, characteristic of a steady state equilibrium is observed. A third regime is observed for sample prepared with $\mathrm{KOH}$ [9]: At the advanced stage, after $400 \mathrm{~min}$, the increase in the amount of $\mathrm{ZnO}$ evidences a secondary precipitation of larger particles. In the steady state equilibrium regime, the hydrolysis induced by $\mathrm{LiOH}, \mathrm{NaOH}$ and $\mathrm{KOH}$ addition allows the formation of 35, 45 and 55\% of $\mathrm{ZnO}$ Q-dot. The increasing yield from $\mathrm{LiOH}$ to $\mathrm{NaOH}$ to $\mathrm{KOH}$ follows the same sequence of the dissociation constant of the alkali base $\left(K_{D}^{\mathrm{MOH}}\right): K_{D}^{\mathrm{LiOH}}<K_{D}^{\mathrm{NaOH}}<K_{D}^{\mathrm{KOH}}$. Moreover, the yield found with $\mathrm{KOH}$ is in agreement with the expected ones from the nominal hydrolysis ratio $[\mathrm{MOH}] /[\mathrm{Zn}]=0.5$ used in the solgel synthesis. Thus the increase in the amount of $\mathrm{ZnO}$ particles observed in the advanced stage (Fig. 4(c); [9]) cannot result from base hydrolysis. We propose that the increase in $\mathrm{ZnO}$ amount after $500 \mathrm{~min}$ of aging is due to the esterification reaction like the one observed in solvothermal synthesis and in non-hydrolytic sol-gel route [25].
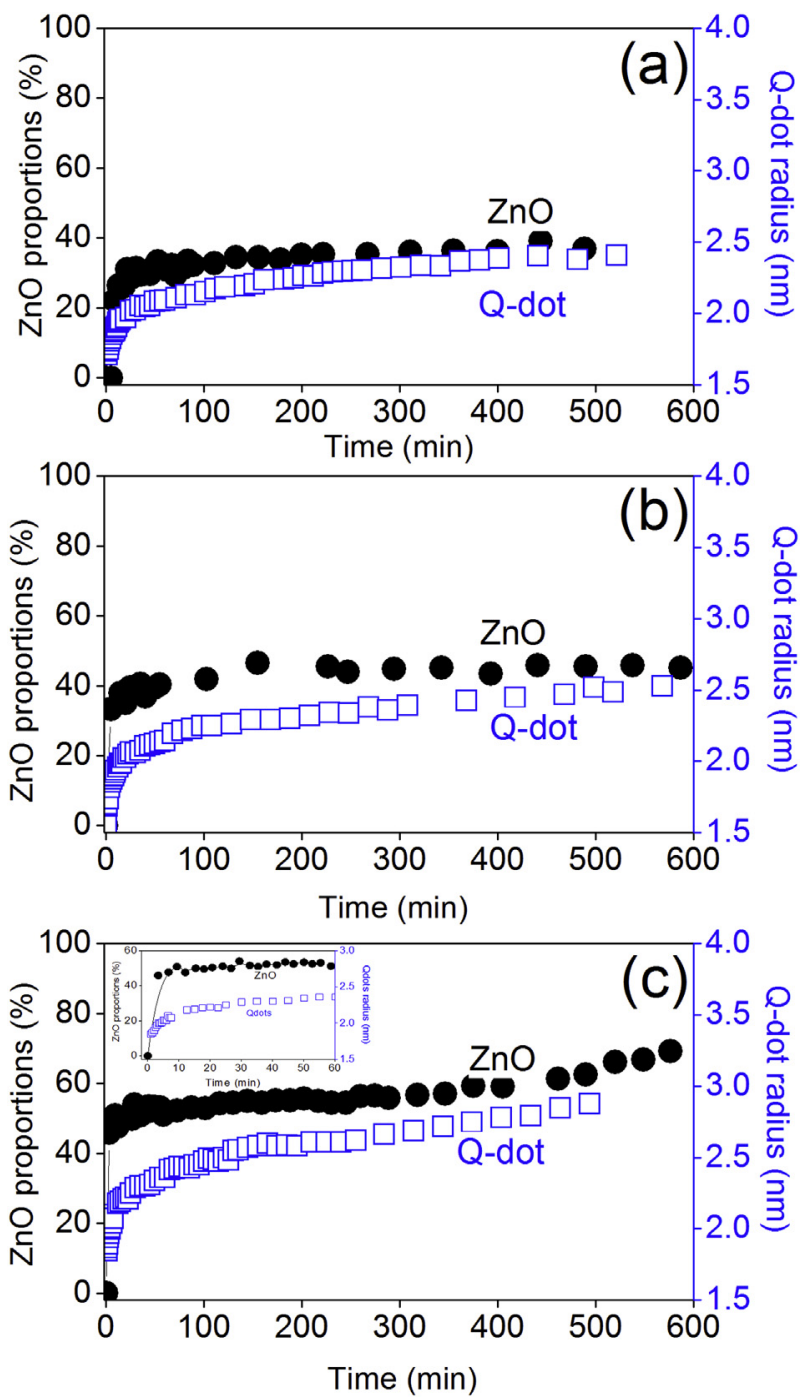

Fig. 4. Time evolution of fractions of $\mathrm{ZnO}$ nanocrystals and of the Q-dot radius determined from EXAFS and UV-Vis spectra, respectively, for samples prepared with $\mathrm{LiOH}(\mathrm{a}), \mathrm{NaOH}$ (b) and $\mathrm{KOH}$ (c) [9] as hydrolyzing agent. The insert shows a magnification of the first $60 \mathrm{~min}$ of reaction for the sample hydrolyzed with $\mathrm{KOH}$. 
The time evolution of the Q-dot radius size is also displayed in Fig. 4 allowing the direct comparison with the percentage of $\mathrm{ZnO}$ formed as colloids. During the first 5 min the fast increase in the quantity of $\mathrm{ZnO}$ occurs together with so fast increase in the Q-dot radius evidencing the so-called nucleation and growth stage. This happens through successive accretion of hydrolyzed zinc species to the preformed nuclei lending to concomitant growth of the amount and size of ZnO nanocrystal. During the quasi-steady state chemical equilibrium the growth of Q-dot radius decelerates continually giving rise to an asymptotic quasi linear regime after $200 \mathrm{~min}$. For the colloid prepared with $\mathrm{KOH}$ this asymptotic regime occurs in the same time period of the secondary precipitation processes. Irrespective of the observed regime the Q-dot growth of colloid hydrolyzed with $\mathrm{KOH} \mathrm{[9]} \mathrm{is} \mathrm{more} \mathrm{pronounced} \mathrm{than} \mathrm{that} \mathrm{observed} \mathrm{for}$ samples prepared with $\mathrm{NaOH}$ and $\mathrm{LiOH}$. This behavior is in agreement with the different time evolution of PE and PL spectra observed for samples prepared with $\mathrm{LiOH}, \mathrm{NaOH}$ and $\mathrm{KOH}$ (Fig. 1).

In order to evaluate the effect of alkali base on the Q-dot growth mechanism at the steady state chemical equilibrium we plotted in Fig. 5 the dependency of the cube of $\mathrm{ZnO}$ Q-dot radius as a function of time. The continuous line is the least-squares fitting of the experimental data with the hyperbolic function that holds $\left(R^{3}=c t \cdot R_{0} /(1+c t)+R_{0}\right.$, c being a constant dependent of the initial concentration of particles and viscosity and $R_{0}$ the initial radii of nanocrystal) [26] for the kinetic of single coalescence step of pristine colloidal nanocrystals involved in the oriented attachment $(\mathrm{OA})$ process limited by the grain-rotation. Irrespective of the nature of the base, a very good agreement between the experimental data and the theoretical predictions is observed during very long periods of time indicating that coalescence by oriented attachment is the dominant mechanism of $\mathrm{ZnO} \mathrm{Q}$-dot growth. After a given time the fitted hyperbolic function achieves an asymptotical constant value, indicating that the majority of primary particles have undergone a coalescence process. This finding is consistent with the evolution of bimodal family of Q-dots evidenced by the two maxima of PE spectra measured after $120 \mathrm{~min}$ of reaction. The average Q-dot size resulting from the coalescence process increases from 2.2, 2.3-2.6 nm for colloids hydrolyzed with $\mathrm{LiOH}, \mathrm{NaOH}$ and

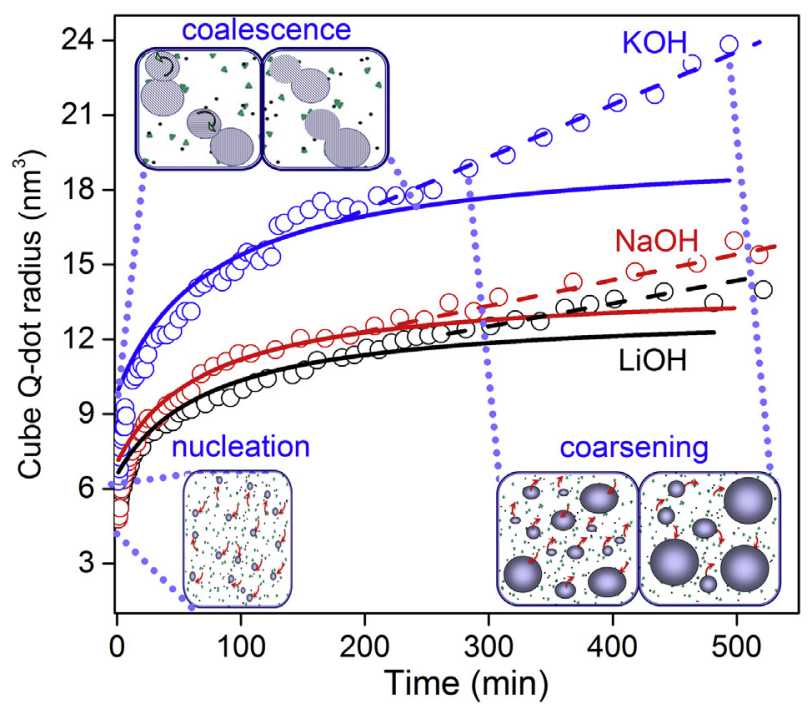

Fig. 5. Time evolution of the cube of the Q-dot radius. The continuous and dashed lines are the best fit of the experimental points with a hyperbolic function and the LSW relation, $\left(\mathrm{R}^{3} \propto \mathrm{t}\right)$, respectively. Insert schematizes the unified $\mathrm{ZnO}$ Q-dot growth mechanism involving coalescence by oriented attachment and coarsening by the Ostwald ripening.
$\mathrm{KOH}$. This feature, in agreement with the PE and PL evolution (Fig. 1), evidences again that the base strength is a useful parameter to fine tuning the $\mathrm{ZnO} \mathrm{Q}$-dot size. The linear dependence observed at the advanced stages is an evidence of the $\mathrm{ZnO} \mathrm{Q}$-dot coarsening controlled by the Ostwald ripening mechanism. This finding shows unequivocally the presence of these two growth regimes irrespective of the base nature, which is also schematically displayed in Fig. 5.

\section{Conclusion}

Irrespective of the alkali base used to promote the hydrolysis of zinc oxide precursor, nucleation and growth of $\mathrm{ZnO} \mathrm{Q}-$ dots occur by the fast conversion of the zinc oxy-acetate in $\mathrm{ZnO}$ nanocrystal. The efficiency of this conversion follows the base strength sequence. Then, after a short transient period, the reaction of $\mathrm{ZnO}$ colloid formation achieves a steady state chemical equilibrium between these two species, and the growth of colloidal nanocrystal occurs by the oriented attachment induced by grain-rotation that results in the coalescence of $\mathrm{ZnO} \mathrm{Q}$-dots. At the advanced stage the $\mathrm{ZnO} \mathrm{Q}-$ dots growth occurs by the coarsening governed by the Ostwald ripening process. All these steps, from growth to coalescence and coarsening, are dependent on the alkali base nature and follows a good correlation with the base strength sequence, $\mathrm{KOH}>\mathrm{NaOH}>\mathrm{LiOH}$. Irrespectively of the nanocrystal growth mechanism, the $\mathrm{ZnO}$ Q-dot prepared from $\mathrm{LiOH}$ and $\mathrm{NaOH}$ present radius smaller than that obtained from the $\mathrm{KOH}$ hydrolyzing agent. It evidences that the $\mathrm{ZnO} \mathrm{Q}$-dot size and the photoluminescence properties can be finely tuned by the choice of the alkali base nature and of the nominal hydrolysis ratio.

\section{Acknowledgements}

The authors want to thank SOLEIL for providing beamtime at the SAMBA beamline and chemistry laboratories and for financial support of the experiments. B.L.C thanks Dr. Sergio Luis Scarpari (IQ/UNESP) for the PL measurements. This work was also partially supported by the FAPESP, CNPq and CAPES/COFECUB cooperation program.

\section{References}

[1] L.E. Brus, J. Chem. Phys. 80 (1984) 4403.

[2] A.L. Efros, A.L. Efros, Sov. Phys. Semicond. 16 (1982) 772.

[3] M. Nirmal, D.J. Norris, M. Kunos, M.G. Bawendi, A.L. Efros, M. Rosen, Phys. Rev. Lett. 75 (1995) 3728.

[4] W. Jiang, A. Singhal, J. Zheng, C. Wang, W.C.W. Chan, Chem. Mater. 18 (2006) 4845.

[5] H.-Q. Shi, W.-N. Li, L.-W. Sun, Y. Liu, H.-M. Xiao, S.-Y. Fu, Chem. Comm. 47 (2011) 11921

[6] S. Li, Z. Sun, R. Li, M. Dong, L. Zhang, W. Qi, X. Zhang, H. Wang, Sci. Rep. 5 (2015) 8475.

[7] C.V. Santilli, S.H. Pulcinelli, M.S. Tokumoto, V. Briois, J. Eur. Ceram. Soc. 27 (2007) 3691.

[8] V. Briois, C. Giorgetti, E. Dartyge, F. Baudelet, M. Tokumoto, S. Pulcinelli, C.V. Santilli, J. Sol-Gel Sci. Technol. 39 (2006) 25

[9] B.L. Caetano, C.V. Santilli, F. Meneau, V. Briois, S.H. Pulcinelli, J. Phys. Chem. C 115 (2011) 4404.

[10] V. Briois, C. Giorgetti, F. Baudelet, S. Blanchandin, M.S. Tokumoto, S.H. Pulcinelli, C.V. Santilli, J. Phys. Chem. C 111 (2007) 3253.

[11] L. Spanhel, M.A. Anderson, J. Am. Chem. Soc. 113 (1991) 2826.

[12] M.S. Tokumoto, V. Briois, C.V. Santilli, S.H. Pulcinelli, J. Sol-Gel Sci. Technol. 26 (2003) 547.

[13] M.S. Tokumoto, S.H. Pulcinelli, C.V. Santilli, A.F. Craievich, J. Non-Cryst. Solids 247 (1999) 176.

[14] E.A. Meulenkamp, J. Phys, Chem. C 102 (1998) 5566.

[15] S.G. Kwon, T. Hyeon, Acc. Chem. Res. 41 (2008) 1696.

[16] E.B. Manaia, R.C.K. Kaminski Renata, B.L. Caetano, V. Briois, L.A. Chiavacci C. Bourgaux, Eur. J. Nanomed 7 (2015) 109.

[17] E. Hosono, S. Fujihara, T. Kimura, H. Imai, J. Sol-Gel Sci. Technol. 229 (2004) 71.

[18] H. Wang, C. Xie, D. Zeng, J. Cryst. Growth 277 (2005) 372.

[19] N.S. Pesika, K.J. Stebe, P.C. Searson, J. Phys. Chem. B 107 (2003) 10412. 
[20] I.M. Lifshitz, V.V. Slyozov, J. Phys. Chem. Solids 19 (1961) 35.

[21] C.Z. Wagner, Elecktrochem. 65 (1961) 581.

[22] C. Pacholski, A. Kornowski, H. Weller, Angew. Chem. Int. 41 (2002) 1188.

[23] D. Vantelon, P. Lagarde, A.M. Flank, E. Berrier, X. Secordel, S. Cristol, C.L. Fontaine, F. Villain, V. Briois, Phase Transit. 82 (2009) 322.
[24] B. Ravel, M.J. Newville, Synchrotron Radiat. 12 (2005) 537.

[25] Z. Hu, D.J.E. Ramírez, B.E.H. Cervera, G. Oskam, P.C. Searson, J. Phys. Chem. B 109 (2005) 11209.

[26] C. Ribeiro, E.J.H. Lee, E. Longo, E.R. Leite, ChemPhysChem 6 (2005) 690. 